\title{
Customer love: Research on the ranking of food and beverage locations
}

\author{
Türk BAHAR
}

Atatürk University, Erzurum, Turkey

Erciş AYSEL

Atatürk University, Erzurum, Turkey

\begin{abstract}
Intense competition in today's markets has meant that customer loyalty is no longer as strong as it used to be. In this context, many researchers have aimed to add new values to the concept of loyalty, particularly focusing on the concept of "love". This study explores customers' feelings towards location in order to identify their preferred - or "most loved" - food and beverage locations. A questionnaire was administered to 395 adult customers living in the city centre of Erzurum, Turkey. The fuzzy Shannon's entropy method is used to identify the weights of each criterion of love, while the fuzzy VIKOR method is used to rank alternative locations. As a result of the analyses, the most prominent expression was found as "I love this location!", and customers' most loved places were identified as those serving regional dishes in Erzurum Province, Turkey. The study uses fuzzy numbers to rank alternatives according to the criteria of love. In addition, the ranking is based on degrees of fuzziness by changing the $\alpha$-cut levels of the fuzzy numbers. The study examines how customers' preferences between alternatives alter via this change.
\end{abstract}

Keywords: retailing, consumer behaviour, customer love, fuzzy Shannon entropy, fuzzy VIKOR.

Please cite the article as follows: Bahar, T and Aysel, E.. (2015), "Customer love: Research on the ranking of food and beverage locations", Management \& Marketing. Challenges for the Knowledge Society, Vol. 10, No. 2, pp. 103-117, DOI: 10.1515/mmcks-2015-0009.

\section{Introduction}

Consumers' cognitive processes are defined as comparisons of perceived performance with expectations. However, emotional processes that affect the majority of consumers are subconscious (Burns and Neisner, 2006). In addition, emotion in the context of the consumption process consists of a series of responses resulting in the use of the product, service or experience (Homburg and Giering, 2001). In relation to customer satisfaction levels, emotional dimensions have been found to be more effective than cognitive dimensions (Jani and Han, 2011). These underlying studies illustrate the importance of emotions within retailing, and suggest that emotionality often takes precedence over cognition for customers. Therefore, emotion-based definitions of love experienced by satisfied customers are shaped in relation to this process.

Studies show that consumers view their relationship with retailers as a rational activity; furthermore, this relationship is seen as a source of pleasure and happiness by consumers. This means that customers can "fall in love" with locations (Kim et al., 2010); however, retailers must make outstanding efforts and create notable differences for customers to be "in love" with them. Thus, while the

Correspondence: Türk Bahar baharsturk@yahoo .com.tr 
MMCKS love occurs on the part of the customer, retailers should endeavour to create it (Kim et al., 2008). Consumers have their own criteria by which to assess their options during the decision-making processes. The selection criteria may change from person to person, and the same person may also exhibit different behaviours at different times, even if in similar scenarios. Likewise, the processes by which consumers' emotions of love develop, and the dimensions of this emotion, also vary.

This study aims to determine which criteria in relation to love have the biggest impact when it comes to the selection of food and beverage locations, and which locations are selected as consumers' first choice. The fuzzy VIKOR method and Shannon's entropy were used in this paper for ranking different types of food and beverage locations. The results of this research based on qualitative criteria contribute to current knowledge about consumer cognitive process.

\section{Literature review}

Within the literature, love is considered a dynamic process which involves an interaction between two people (Kim, 2007). When the concept is applied to the relationship between retailer and customer, the definition does not change much, and again, a two-way interaction is involved. In addition, the behaviour of individuals affects the relationship (Whang et al., 2004); thus, consumers' behavioural actions are very important (Sautter et al., 2004).

Perhaps the most important concept in relation to love is commitment. Commitment, in general, can be defined as an emotionally charged relationship between people and a special object or entity (Parkinson et al., 2004). Individuals have long been shown to exhibit emotional loyalty to the elements of consumption throughout their lives (Whang et al., 2004). During their lifetime, consumers interact with thousands of elements of consumption, but only experience intense emotional commitment to a small number of these. The power of commitment may vary; furthermore, strong emotions incite passion and love (Klcinc and Baker, 2004).

In the literature, two basic concepts are frequently discussed that are considered to be similar to customer love; each of these concepts are essentially different from one another. The first concept is customer satisfaction. It is normal for customers to develop a sense of satisfaction with their favourite retailer, and this satisfaction can be said to form the basis of the customers' love. However, satisfaction and love are not the same thing. Satisfaction has been examined according to two dimensions (Ladhari, 2009). The first is a specific processoriented satisfaction, which may occur after the consumer makes contact with a transaction, event or retailer. This concept includes the consumers' reactions and experiences. Customer love differs from this concept: while specific satisfaction may be felt immediately after a visit to a retailer, customer love involves contact more than once, and evolves over time. The second satisfaction dimension is cumulative satisfaction. Here, consumers conduct an evaluation based on emotional and all other relationships with the retailer. This differs from love in that cumulative satisfaction includes more cognitive evaluation, while customer love includes a much more emotional orientation (Jones and Suh, 2000). In addition, cumulative satisfaction involves a rational assessment that considers whether expectations have been met, after the period of contact with the retailer. 
Customer love, on the other hand, arises as a result of the emotional experience with the retailer (Carroll and Ahuvia, 2006).

The second basic concept that is frequently discussed in the literature is attitude. Attitude is a reaction or emotion that individuals develop in relation to objects, events or conditions (Ajzen, 2005). Customer love again differs from attitude, since there is no need for direct contact in order for an attitude to form (for instance, consumers can develop a positive attitude about a retailer without the need to share any experience with them). In addition, customers can develop a positive attitude towards several retailers at once, whereas love is felt only towards the retailers that are most favoured, and deemed most important, to the customer, and requires continuous contact (Ahuvia, 2005). Furthermore, consumers tend to protect places they love even in negative situations; the same cannot be said for retailers towards whom customers simply have a positive attitude. Consumers also do not avoid changing to equivalent retailers under any conditions if they simply develop a positive attitude towards the original retailer (Thomson et al., 2005).

Consequently, love as expressed in the terms described can be considered a criterion based on which consumers select food and beverage locations. The main objective of this paper is to determine food and beverage locations in terms of several selection criteria using both the fuzzy Shannon's entropy and VIKOR methods.

\section{Research methodology}

In this section, the weights of each love criterion are calculated using fuzzy Shannon's entropy. Following this, consumers' preferences of food and beverage locations are ranked using fuzzy VIKOR.

\section{Fuzzy sets and fuzzy numbers}

Crisp data is often insufficient for expressing real-life conditions, since judgements containing personal preferences are often vague and difficult to determine with an exact numerical value. Using linguistic statements instead of numerical values that is, evaluating by means of linguistic variables that provide the ratings and weights of the criteria in a problem - is a more realistic approach (Liu and Wang, 2007; Chen, 2000, 2001; Herrera and Herrera-Viedma, 2000; Li, 2005; Zadeh, 2009).

In such cases, a fuzzy set $\widetilde{A}$ identified by the membership function $\mu_{\widetilde{A}}(X)$, which is a real number defined in the interval $[0,1]$ for each element $x$ in the universe of discourse $X$ can be determined (Chaghooshi et al., 2012). There are many types of membership functions (see Zadeh 2008); however, the most often used are triangular and trapezoidal membership functions. Thus, triangular membership functions will be used in our study. The triangular membership function is defined according to three parameters, $l, m$ and $u$, which form the shape of the components, as shown below (Figure 1).

$$
\mu_{\tilde{A}}(x ; l, m, u)=\left\{\begin{array}{l}
l \leq x \leq m, \frac{(x-l)}{(m-l)} \\
m \leq x \leq u, \frac{(u-x)}{(u-m)} \\
x>u \text { or } x<l, 0
\end{array}\right.
$$




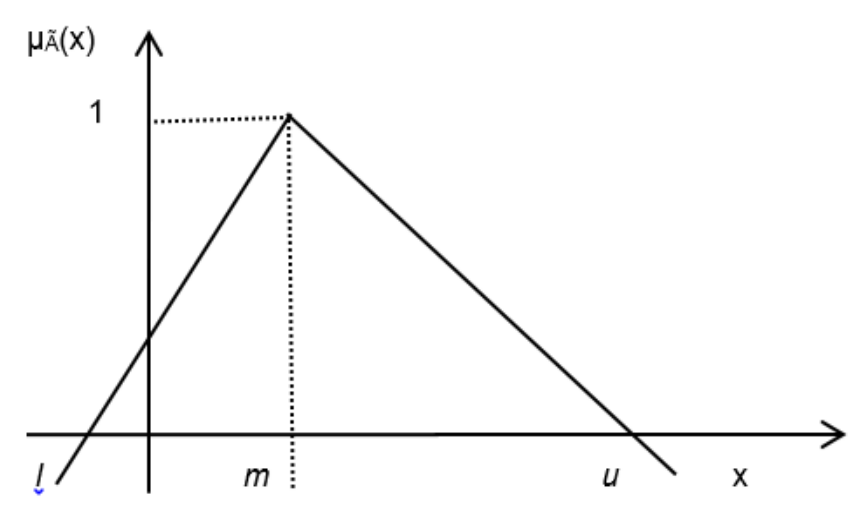

Figure 1. A triangular fuzzy number $\widetilde{\mathbf{A}}$

Source: Authors' own contribution.

$m$ is the mid-point of l's and $u$ 's, but not necessarily to be the mean of them (Zadeh, 2008). In this study, the interval of the data consists of the criteria values, which are taken as triangular fuzzy numbers (where the triangular fuzzy number $\tilde{A}$ is defined by the triplet $(l, m, u)$, as indicated above).

Fuzzy interval Shannon's entropy based on $\alpha$-level sets

Shannon's entropy (Shannon, 2001) is a concept that plays an important role in information theory. In the simplest form of the concept, information is defined as the measurement of uncertainty. The approach has been extended to different scientific fields, such as physics and social sciences (Ghorbani et al., 2012). Lotfi and Fallahnejad (2010) extended Shannon's entropy to interval data cases.

The elements of the decision matrix are presented as intervals due to difficulties related to determining the exact values. The structure of the alternative performance matrix in the interval data case is expressed as shown in Table 1, where $\left[x_{i j,}^{l} x_{i j}^{u}\right]$ is the rating of alternative $i$ with respect to criterion $j$, and $\left[w^{l}{ }_{j,} w^{u}{ }_{j}\right]$ is the weight of criterion $j$ :

Table 1. The structure of the alternative performance when the data are considered in as intervals

\begin{tabular}{|c|c|c|c|c|}
\hline & Criterion 1 & Criterion 2 & $\cdots$ & Criterion n \\
\hline Alternative 1 & {$\left[x_{11}^{l}, x_{11}^{u}\right]$} & {$\left[x_{12}^{l}, x_{12}^{u}\right]$} & $\cdots$ & {$\left[x_{1 n}^{l}, x_{1 n}^{u}\right]$} \\
\hline Alternative 2 & {$\left[x_{21}^{l}, x_{21}^{u}\right]$} & {$\left[x_{22}^{l}, x_{22}^{u}\right]$} & $\cdots$ & {$\left[x_{2 n}^{l}, x_{2 n}^{u}\right]$} \\
\hline$\vdots$ & $\vdots$ & $\vdots$ & $\cdots$ & $\vdots$ \\
\hline Alternative m & {$\left[x_{m 1}^{l}, x_{m 1}^{u}\right]$} & {$\left[x_{m 2}^{l}, x_{m 2}^{u}\right]$} & $\cdots$ & {$\left[x_{m n}^{l}, x_{m n}^{u}\right]$} \\
\hline & {$\left[w_{1}^{l}, w_{1}^{u}\right]$} & {$\left[w_{2}^{l}, w_{2}^{u}\right]$} & & {$\left[w_{n}^{l}, w_{n}^{u}\right]$} \\
\hline
\end{tabular}

Source: Authors' own contribution.

\section{Proposed approach}

Step 1: The normalized values $p^{l}{ }_{i j}$ and $p^{u}{ }_{i j}$ are calculated as:

$p_{i j}^{l}=\frac{x_{i j}^{l}}{\sum_{j=1}^{m} x_{i j}^{u}}, p^{u}{ }_{i j}=\frac{x_{i j}^{u}}{\sum_{j=1}^{m} x_{i j}^{u}}, j=1, \ldots . ., m, i=1, \ldots . ., n$

Step 2: The lower bound $h^{l}{ }_{i}$ and upper bound $h^{u}{ }_{i}$ of the interval entropy can be obtained by:

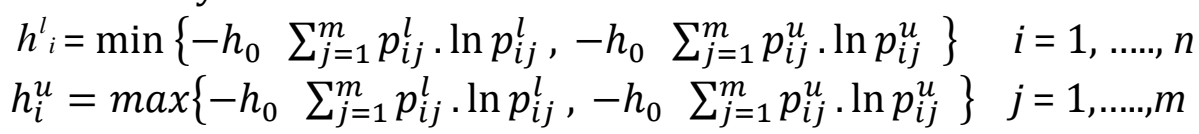


where $h_{0}$ is equal to $(\ln m)^{-1}$ and $p_{i j}^{l} \cdot \ln p_{i j}^{l}, p_{i j}^{u} \cdot \ln p_{i j}^{u}$, is defined as 0 if $p_{i j}^{l}=0$ or $p_{i j}^{u}=0$.

Step 3: The lower and the upper bound of the interval of diversification $d_{i}^{l}$ and $d_{i}^{u}$ is set as the degree of diversification as follows:

$$
d_{i}^{l}=1-h_{i}^{u}, \quad d_{i}^{u}=1-h_{i}^{l}, i=1, \ldots . ., n
$$

Step 4: $w_{i}^{l}=\frac{d_{i}^{l}}{\sum_{s=1}^{n} d_{s}^{u}}, w_{i}^{u}=\frac{d_{i}^{u}}{\sum_{s=1}^{n} d_{s}^{l}}$ is set as the lower and upper bound of the interval weight of attribute I.

Here, the interval $\left[w_{i}^{l}, w_{i}^{u}\right]$ is named as the weight of the ith criterion obtained from the interval entropy method. If all of the alternatives were deterministic data, then this would be $x_{i j}^{l}=x_{i j}^{u}$ and also $p_{i j}^{l}=p_{i j}^{u}$. Thus, it would be $h_{i}^{l}=h_{i}^{u}$ and therefore $d_{i}^{l}=d_{i}^{u}$ then $w_{i}^{l}=w_{i}^{u}$ (the basic entropy weight). This also shows that the interval entropy weight in the case of the deterministic decision matrix corresponds with the ordinary entropy weight. However, if at least one of the numbers is an interval, all weights will be in interval form, even for criteria with crisp data. The reason for this is that the final entropy weight is dependent on the degree of diversification $\left(d_{i}\right)$ of all criteria based upon the fourth step of the entropy method $w_{i}=\frac{d_{i}^{l}}{\sum_{s=1}^{n} d_{s}}$. Thus, if a criterion is in the interval form, its degree of diversification will be obtained in the interval form as well. Therefore, the weight of the crisp criteria will alter based on the alteration of the degree of diversification of an interval criterion in its interval degree of diversification (Lotfi and Fallahnejad, 2010).

\section{The fuzzy VIKOR method}

The VIKOR method was developed as a multi-criteria decision making (MCDM) method to solve a discrete multi-criteria problem with no commensurable and conflicting criteria (Ehrgott, 2005). It focuses on ranking and selecting from a set of alternatives, and determines compromise solutions for a problem with conflicting criteria, which can help the decision makers to reach a final decision. The compromise solution is a feasible solution that is closest to the ideal (Opricovic and Tzeng, 2004). VIKOR is based on old ideas of compromise programming (Chen and Wang, 2009; Kabir, 2014). An extension of VIKOR to determine a fuzzy compromise solution for multi-criteria is presented by Opricovic (2007).

The fuzzy VIKOR method has been developed as a fuzzy MCDM method to solve discrete fuzzy multi-criteria problems with no commensurable or conflicting criteria. The background of this method, including aggregation, normalization, decision maker's (DM's) preference assessment, and operations on fuzzy numbers are discussed, as a study of rationality that in some way justifies the fuzzy VIKOR method. This new method provides a contribution to the practice of MCDM.

The fuzzy VIKOR method has been developed to determine the compromise solution of the fuzzy multi-criteria problem ${ }_{j}^{m c o}\left\{\left(\widetilde{f_{l}}\left(A_{j}\right), j=1, \ldots, J\right), i=\right.$ $1, \ldots, n\}$

where:

$j$ is the number of feasible alternatives,

$A_{j}=\left\{x_{1}, x_{2}, \ldots\right\}$ is the $j$ th alternative obtained (generated) with certain values of system variables $x$,

$f_{i j}$ is the value of the $i$ th criterion function for the alternative $A_{j}$, 
MMCKS $n$ is the number of criteria.

A multi-criteria operator (MCO) denotes the operator within the MCDM procedure for selecting the best (compromise) alternative in a multi-criteria sense.

108 Alternatives can be generated and their feasibility tested using mathematical models (determining variables $x$ ), physical models, and/or experiments on the existing system or other similar systems. Constraints are seen as high-priority objectives, which must be satisfied via the alternative-generating process. In this paper, it is assumed that the alternatives are evaluated by the triangular fuzzy numbers $\tilde{f}_{i j}=\left(l_{i j}, m_{i j}, r_{i j}\right), i=1, \ldots, n, \quad j=1, \ldots, J$. The set of criteria representing benefits (good effects) is denoted by $I^{b}$, and a set $I^{c}$ for costs. Here, $\left|I^{b} \cup I^{c}\right|=n$, where $|$.$| denotes a cardinal number. The ranking algorithm within$ VIKOR entails the following steps:

Step 1. Determine the ideal $\tilde{f}_{i}^{*}=\left(l_{i}^{*}, m_{i}^{*}, r_{i}^{*}\right)$ and the anti-ideal $\tilde{f}_{i}^{o}=\left(l_{i}^{o}, m_{i}^{o}, r_{i}^{o}\right)$ values of all criteria functions, $i=1,2, \ldots, n$.

$\tilde{f}_{i}^{*}={ }_{j}^{M A X} \tilde{f}_{i j}, \quad \tilde{f}_{i}^{o}={ }_{j}^{M I N} \tilde{f}_{i j}, \quad$ for $i \in I^{b}$

$\tilde{f}_{i}^{*}={ }_{j}^{M I N} \tilde{f}_{i j}, \quad \tilde{f}_{i}^{o}={ }_{j}^{M I N} \tilde{f}_{i j}, \quad$ for $i \in I^{c}$

Step 2. Compute the normalized fuzzy difference $\tilde{d}_{i j}, j=1, \ldots, J, i=1, \ldots, n$ :

$\widetilde{d}_{i j}=\left(\tilde{f}_{i}^{*} \ominus \tilde{f}_{i j}\right) /\left(r_{i}^{*}-l_{i}^{o}\right) \quad$ for $i \in I^{b}$

$\tilde{d}_{i j}=\left(\tilde{f}_{i j} \ominus \tilde{f}_{i}^{*}\right) /\left(r_{i}^{o}-l_{i}^{*}\right) \quad$ for $i \in I^{c}$

Step 3. Compute $\tilde{S}_{j}=\left(S_{j}^{l}, S_{j}^{m}, S_{j}^{r}\right)$ and $\tilde{R}_{j}=\left(R_{j}^{l}, R_{j}^{m}, R_{j}^{r}\right), j=1,2, \ldots, J$

Using the relations:

$\tilde{S}_{j}=\sum_{i=1}^{n} \oplus\left(\widetilde{w}_{i} \otimes \tilde{d}_{i j}\right)$

$\tilde{R}_{j}=\underset{i}{\operatorname{MAX}}\left(\widetilde{w}_{i} \otimes \tilde{d}_{i j}\right)$

Where $\tilde{S}$ is a fuzzy weighted sum, $\widetilde{R}$ is a fuzzy operator MAX, and $\widetilde{w}_{i}$ are the weights of the criteria, which express the DM's preference as the relative importance of the criteria.

Step 4. Compute the values $\tilde{Q}_{j}=\left(Q_{j}^{l}, Q_{j}^{m}, Q_{j}^{r}\right) j=1,2, \ldots, J$ using the relation:

$\tilde{Q}_{j}=\vartheta\left(\tilde{S}_{j} \ominus \tilde{S}^{*}\right) /\left(S^{o r}-S^{* 1}\right) \oplus(1-\vartheta)\left(\tilde{R}_{j} \ominus \tilde{R}^{*}\right) /\left(R^{o r}-R^{* 1}\right)$

Where: $\tilde{S}^{*}={ }_{j}^{M I N} \tilde{S}_{j}, S^{\text {or }}=\max _{j} S_{j}^{r}, \tilde{R}^{*}={ }_{j}^{M I N} \tilde{R}_{j}, \quad R^{\text {or }}=\max _{j} R_{j}^{r}$, and $\vartheta$ is introduced as a weight for the strategy of "the majority of criteria" (or "the maximum group utility"), whereas $1-\vartheta$ is the weight of the individual regret. These strategies could be compromised by $\vartheta=5$, and here $\vartheta$ is modified as $\vartheta=(n+1) / 2 n$ (from $\vartheta+0.5(n-1) / n=1)$ since the criterion ( 1 of $n$ ) related to $R$ is also included in $S$. The best values of $S$ and $R$ are denoted by $\tilde{S}^{*}$ and $\tilde{R}^{*}$, respectively.

Step 5. Rank the alternatives by sorting the core values $Q_{r}^{m}, j=1,2, \ldots, J$ in decreasing order. The ordering obtained is denoted by $\{A\}_{Q^{m}}$.

Step 6. Determine the fuzzy ranking as follows: 
The $j$ th ranking position in $\{A\}_{Q^{m}} A^{(j)},=1, \ldots, J$, is confirmed if $\begin{gathered}M I N \\ k \in J^{j}\end{gathered} Q^{(k)}=Q^{(j)}$, where $J^{j}=\{j, j=1, \ldots, J\}$ and $Q^{(k)}$ is the fuzzy merit for the alternative $A^{(k)}$ at the $k$ th position in $\{A\}_{Q^{m}}$. Confirmed ordering represents "exact" fuzzy ranking $\{A\}_{\tilde{Q}}$,

although the set $\{A\}_{\tilde{Q}}$ does not necessarily represent a complete ordering (it may be a partial ranking).

Step 7. Conduct defuzzification of $\tilde{S}_{j}, \tilde{R}_{j} \tilde{Q}_{j}, j=1,2, \ldots, J$ using the relations Crisp $(\widetilde{N})=(2 m+l+r) / 4$

Here, the "second weighted mean" defuzzification method is applied to convert the fuzzy number into a crisp value.

Step 8. Rank the alternatives, with the crisp values $S, R$ and $Q$ being placed in decreasing order. The result is three ranked lists $\{A\}_{S},\{A\}_{R},\{A\}_{Q}$, plus a compromise solution alternative $\left(A^{(1)}\right)$ which is the best ranked by the measure $Q$ (in $\{A\}_{Q}$ ) if the following two conditions are satisfied:

C1. "Acceptable Advantage": Adv $\geq D Q$

Where $\operatorname{Adv}=\left[Q\left(A^{(2)}\right)-Q\left(A^{(1)}\right)\right] /\left[Q\left(A^{(j)}\right)-Q\left(A^{(1)}\right)\right]$ is the advantage rate of the alternative $A^{(1)}$ ranked first, $A^{(2)}$ is the alternative in the second position in $\{A\}_{Q}$, and the threshold $D Q=1 /(\mathrm{J}-1)$.

C2. "Acceptable stability in decision making":

The alternative $A^{(1)}$ must also be the best ranked by $S$ and/or $R$. If one of the conditions is not satisfied, then a set of compromise solutions should be proposed. These consist of:

- Alternatives $A^{(1)}$ and $A^{(2)}$ if only condition C2 is not satisfied, or

- Alternatives $A^{(1)}, A^{(2)}, \ldots A^{(M)}$ if condition C1 is not satisfied; $A^{(M)}$ is determined by the relation $\mathrm{Q}\left(A^{(M)}\right)-\mathrm{Q}\left(A^{(1)}\right)<\mathrm{DQ}$ for maximum $M$.

Determine crisp trade-offs, $t r_{i k}=\left(D_{i} w_{k}\right) /\left(D_{k} w_{i}\right), \mathrm{k} \neq \mathrm{i}, \mathrm{k}=1 \ldots . \mathrm{n}$, where $t r_{i k}$ is the number of units of the $i$ th criterion evaluated in the same manner as one unit of the criterion $D_{i}=r_{i}^{*}-l_{i}^{o}$ for $i \in I^{b}, D_{i}=r_{i}^{o}-l_{i}^{*}$, for $i \in I^{c}$, and $\mathrm{w}=\operatorname{Crisp}(\widetilde{w})$ obtained via the defuzzification used in step (vii). The index i is given by the VIKOR user. The VIKOR method introduces these trade-offs as a result of the normalization used in Eq. (5) for the operations in (6) and (7).

Step 9. The DM may give a new value of $t r_{i k}, \mathrm{k} \neq \mathrm{i} \mathrm{k}=1 \ldots \mathrm{n}$, if he or she does not agree with the computed values in step (x). The new weight values are computed $w_{k}=\left|\left(D_{k} w_{i}-t r_{i k}\right) / D_{i}\right|, \mathrm{k} \neq \mathrm{i} \mathrm{k}=1 \ldots . \mathrm{n}$, and $w_{i}$ is the previous value within the step.

Step 10. Perform a new ranking from step (iii) using $\widetilde{w}_{k}=\left(w_{k}, w_{k}, w_{k}\right), \mathrm{k}=1 \ldots . . \mathrm{n}$. The trade-offs determined in step (x) could help the DM to assess new values, although this task is very difficult.

Step 11. The VIKOR algorithm ends when no new values are obtained in step $\left(x_{i}\right)$.

\section{Application}

In this section, we used existing scales to measure all constructs. For customer love, we applied a modified version of the scale used by Kim (2007). From a conceptual standpoint, this scale captures the complexity of the feeling of customer love. It contains 10 expressions, including: "This is a wonderful location", "This location makes me feel good", "This location is totally awesome", "This location makes me very happy", "I love this location!", "This location is a pure delight", "I am passionate about this location", "I'm very attached to this location". And reverse expressions: "I have neutral feelings about this location", "I have no particular 
feelings this location". The reverse expressions are not statistically significant, and therefore have not been included in the analysis. The reliability and mean and standard deviation of the scales are summarized in Table 2.

Data were collected using face-to-face interviews with the help of marketing researchers that specialize in consumer surveys. A total of 395 respondents participated in the study. Food and beverage locations offering regional dishes in Erzurum Province were categorized and the respondents were asked to select the location categories they visited most, and would miss most if these locations closed. They were then asked a number of demographic questions.

Frequency analyses were applied to the demographic data. The majority (41.8\%) of the participants were aged between 26 and 33. More than half (63.0\%) were male, and more than half (57.0\%) also reported a monthly income of over 2001 Turkish liras (approximately 745 Euro). Additionally, 48.6\% of the participants had a four-year college degree, and $46.1 \%$ were public- or privatesector employees.

Table 2. Mean and standard deviation of customer love

\begin{tabular}{|l|c|c|}
\hline & Mean & Standard Deviation \\
\hline Customer Love (Cronbach Alpha= 0,83) & & \\
\hline A1- This is a wonderful location. & 3.97 & 0.702 \\
\hline A2- This location makes me feel good. & 3.48 & 0.847 \\
\hline A3- This location is totally awesome. & 3.67 & 0.902 \\
\hline A5- This location makes me very happy. & 3.92 & 0.866 \\
\hline A6- I love this location! & 3.24 & 0.975 \\
\hline A8- This location is a pure delight. & 3.01 & 0.995 \\
\hline A9- I am passionate about this location. & 3.13 & 1.012 \\
\hline A10- I'm very attached to this location. & 4.04 & 0.766 \\
\hline
\end{tabular}

Source: Authors' own research.

Table 2 displays a rank according to the mean value determined in accordance with the scores given to the criteria of customer love. The standard deviations are also shown for each criterion. From here, it can be observed that the scores assigned changed from person to person, which suggests that differences arise due to variations in personal views. For such situations, fuzzy sets were introduced by Zadeh (1965) to represent and manipulate data and information possessing non-statistical uncertainties, and to provide formalized tools for dealing with the imprecision intrinsic in related problems. Fuzzy logic thus provides an inference morphology that enables approximate human reasoning capabilities to be applied to knowledge-based systems. The theory of fuzzy logic provides a mathematical strength to capture the uncertainties associated with human cognitive processes, such as thinking and reasoning (Kahraman et al., 2007).

In this paper, the importance weights of various alternatives are considered as linguistic variables, and are determined based on the opinions of the participants. Because linguistic assessments merely approximate the subjective judgment of DM, we considered linear triangular membership functions to be adequate for capturing the vagueness of these linguistic assessments. We ranked food and beverage locations using a fuzzy VIKOR method, which is a multi-criteria decision technique, by means of triangular fuzzy numbers based on variables relating to love, and used fuzzy Shannon's entropy to handle a criterion of love variables, and to calculate their weights.

There are many different forms to express triangular fuzzy numbers (TFNs) in the literature. Here, we preferred the linguistic terms represented by TFNs 
associated with a Likert scale to score the alternatives under the criteria. The Likert scale, expressed by triangular fuzzy numbers, is shown in Table 3.

Table 3. Triangular fuzzy Likert scale

\begin{tabular}{|c|c|c|c|c|c|c|}
\hline & \multicolumn{3}{|c|}{ Fuzzy Likert scale } & \multicolumn{3}{|c|}{ Fuzzy reciprocal Likert scale } \\
\hline Absolutely Disagree & $(1$, & 1, & 1) & $(1$ & 1, & 1) \\
\hline I Don't Agree & $(1$, & 2, & 3) & $(0.33$ & 0.50 & 1) \\
\hline Cannot Say & $(2$, & 3 , & 4) & $(0.25$ & 0.33, & $0.50)$ \\
\hline I Agree & $(3$, & 4, & 5) & $(0.20$ & 0.25 & $0.33)$ \\
\hline Absolutely Agree & $(4$, & 5 , & 6) & $(0.17$ & 0.20 & $0.25)$ \\
\hline
\end{tabular}

Here, it is suggested that DM use linguistic variables (shown in Table 3 evaluate the importance of the criteria and the ratings of alternatives with respect to the various criteria. If we assume that a decision group consists of $K=395$ people, after determining the importance degree of the criteria, the rating of alternatives with respect to each criterion is calculated as:

$\widetilde{\mathrm{x}_{l j}}=\frac{1}{K}\left[\widetilde{x_{l \jmath}^{1}} \oplus \widetilde{x_{l j}^{2}} \oplus \ldots \oplus \widetilde{x_{l j}^{k}}\right]$

Where $\widetilde{\mathrm{x}_{l \jmath}}$ is the rating of the $k$ th DM. As stated above, a fuzzy multi-criteria group decision-making problem can be concisely expressed in matrix format, as shown in Table 4. As shown here, all criteria are intervals.

Table 4. Matrix of alternatives and criteria

\begin{tabular}{|c|c|c|c|c|c|c|c|c|c|c|}
\hline & \multicolumn{3}{|c|}{$\mathrm{Al}_{1}$} & \multicolumn{3}{|c|}{$A_{2}$} & $\ldots$ & \multicolumn{3}{|c|}{$\mathrm{A}_{10}$} \\
\hline Soup Restaurant & $(2.73$ & 3.73 & 4.73) & $(2.27$ & 3.27 & 4.27) & $\ldots$ & $(1.87$ & 2.87 & 3.87) \\
\hline Craft Restaurant & $(2.54$ & 3.54 & 4.43) & $(2.62$ & 3.62 & $4,51)$ & $\ldots$ & $(2.57$ & 3.54 & $4.51)$ \\
\hline Fast-Food Restaurant & $(2.96$ & 3.96 & $4.82)$ & $(2.40$ & 3.38 & 4.29) & $\ldots$ & $(2.18$ & 2.98 & $3.78)$ \\
\hline Kebab Restaurant & $(2.97$ & 3.97 & $4.80)$ & $(2.51$ & 3.51 & $4.41)$ & $\ldots$ & $(2.21$ & 3.04 & $3.87)$ \\
\hline Cake Shop & $(3.06$ & 4.06 & 4.88) & $(2.53$ & 3.53 & $4.35)$ & $\ldots$ & $(2.00$ & 2.94 & $3.88)$ \\
\hline Regional Food Restaurant & $(3.07$ & 4.06 & $4.81)$ & $(2.48$ & 3.47 & $4.36)$ & $\ldots$ & $(2.29$ & 3.19 & $4.09)$ \\
\hline
\end{tabular}

Source: Authors' own research.

We want to obtain a weight for each criterion by using the proposed approach. In Table 5, the normalized data are presented.

Table 5. Normalized interval decision matrix using $\alpha$-level sets

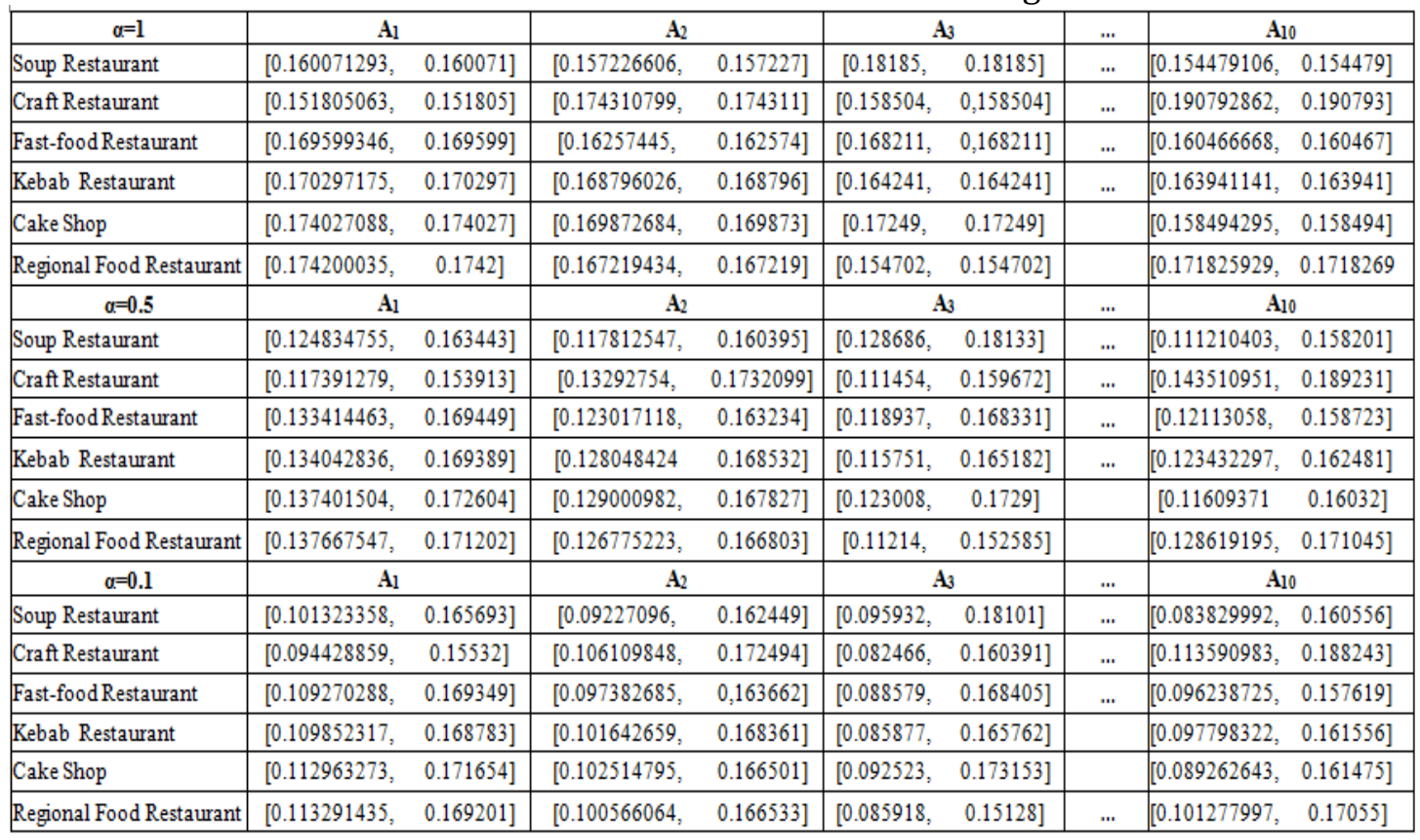

Source: Authors' own research. 
The lower bound $h_{i}^{l}$ and upper bound $h_{i}^{u}$ of the interval entropy, and the lower bound $d_{i}^{l}$ and upper bound $d_{i}^{u}$ of the interval diversification values for different $\alpha$-cut levels obtained by using equations 2, 3 and 4 are shown in Table 6.

Table 6. The values of $h_{i}^{l}, h_{i}^{u}, d_{i}^{l}$ and $d_{i}^{u}$

\begin{tabular}{|c|c|c|c|c|c|c|}
\hline & \multicolumn{2}{|c|}{$\theta=1$} & \multicolumn{2}{|c|}{$a=0.5$} & \multicolumn{2}{|c|}{$0=0.1$} \\
\hline & {$\left[h_{i}^{h}, h_{i}^{\prime \prime}\right]$} & {$\left[d_{1}^{1}, d_{i}^{u}\right]$} & {$\left[h_{i}^{h}, h_{i}^{u}\right]$} & {$\left[d_{1}^{1}, d_{i}^{k}\right]$} & {$\left[h_{i}^{h}, h_{i}^{h}\right]$} & {$\left[d_{i} ; d_{i}^{k}\right]$} \\
\hline Al & {$[0.999326,0.999326]$} & {$[0.00,0.000674]$} & {$[0.890211,0.999585]$} & {$[0.000415,0.109789]$} & {$[0.799448,0.999706]$} & {$[0.000294,0.200552]$} \\
\hline$A_{2}$ & {$[0.999698,0.999698]$} & {$[0.000302,0.000302]$} & {$[0.874660,0.999835]$} & {$[0.000165,0.12534]$} & {$[0.771094,0.999894]$} & {$[0.000106,0.228906]$} \\
\hline$A_{3}$ & {$[0.999196,0.999196]$} & {$[0.000804,0.000804]$} & {$[0.845181,0.999153]$} & {$[0.000847,0.154819]$} & {$[0.718446,0.999113]$} & {$[0.000887,0.281554]$} \\
\hline As & {$[0.998962,0.998962]$} & {$[0.001038,0.001038]$} & {$[0.893065,0.999368]$} & {$[0.000632,0.106935]$} & {$[0.804482,0.999574]$} & {$[0.000426,0.195518$} \\
\hline As & {$[0.997761,0.997761]$} & {$[0.002239,0.002239]$} & {$[0.863548,0.998279]$} & {$[0.001721,0.136452]$} & {$[0.752622,0.99851]$} & {$[0.00149,0.247378]$} \\
\hline As & {$[0.999352,0.9993552]$} & {$[0.000648,0.000648]$} & {$[0.862406,0.999437]$} & {$[0.000563,0.137594]$} & {$[0.7503,0.999452]$} & {$[0.000548,0.2497]$} \\
\hline Al & {$[0.998579,0.998579]$} & {$[0.001421,0.001421]$} & {$[0.865382,0.998824]$} & {$[0.001176,0.134618]$} & {$[0.756313,0.998934]$} & {$[0.001066,0.243687]$} \\
\hline$A 10$ & {$[0.998579,0.998579]$} & {$[0.001421,0.001421]$} & {$[0.865382,0.998824]$} & {$[0.001176,0.134618]$} & {$[0.756313,0.998934]$} & {$[0.001066,0.243687]$} \\
\hline
\end{tabular}

Source: Authors' own research.

The obtained weights and the corresponding rank of each criterion for different $\alpha$-level sets are presented in Table 7. As can be seen from Table 7, the rankings under different $\alpha$-levels might vary considerably.

Table 7. The interval and crisp weights of the criteria

\begin{tabular}{|c|c|c|c|c|c|c|c|c|c|}
\hline & \multicolumn{3}{|c|}{$\theta=l$} & \multicolumn{3}{|c|}{$a=0.5$} & \multicolumn{3}{|c|}{$0=0.1$} \\
\hline & {$\left[w_{i}^{l}, w_{i}^{k}\right]$} & {$\left[w_{i}\right]$} & $\begin{array}{c}\text { Nomalized } \\
{\left[w_{i}\right]}\end{array}$ & {$\left[w_{i}^{l}, w_{i}^{k}\right]$} & {$\left[w_{i}\right]$} & $\begin{array}{c}\text { Nomalized } \\
{\left[w_{i}\right]}\end{array}$ & {$\left[w_{i}^{l}, w_{i}^{u}\right]$} & {$\left[w_{i}\right]$} & $\begin{array}{c}\text { Nomalized } \\
{\left[w_{i}\right]}\end{array}$ \\
\hline $\mathrm{Al}_{\mathrm{l}}$ & {$\left[\begin{array}{lll}0.08, & 0.078886\end{array}\right]$} & {$[0.078886]$} & {$[0.078886]$} & {$[0.000399,16.39839]$} & {$[8.199393]$} & {$[0.105548]$} & {$[0.000155,34.09617]$} & {$[17,04817$} & {$[0,106056]$} \\
\hline$A_{2}$ & {$[0.035318,0.035318]$} & {$[0.035318]$} & {$[0.035318]$} & {$[0.000159,18.7212]$} & 99.360678 & {$[0.120496]$} & {$[5.62 \mathrm{E}-05,38.91676$} & {$[19,45841$} & {$[0,121051]$} \\
\hline$A_{3}$ & {$[0.094028,0.094028]$} & {$[0.094028]$} & {$[0.094028]$} & {$[0.000815,23.12424]$} & {$[11.56253$} & [0.14884] & {$[0.000469,47.86751]$} & {$[23,93399]$} & {$[0,148893]$} \\
\hline As & {$[0.121473,0.121473]$} & {$[0.121473]$} & {$[0.121473]$} & {$[0.000608,15.97215]$} & [7.98638] & {$[0.102806]$} & {$[0.000225,33.24034$} & {$[16,62028$} & {$[0,103395]$} \\
\hline$A_{0}$ & {$[0.26195,0.26195]$} & [0.26195] & [0.26195] & {$[0.001654,20.38091]$} & {$[10.19128$} & {$[0.131188]$} & {$[0.000788,42.05715]$} & {$[21,02897$} & {$[0,130821]$} \\
\hline$A_{8}$ & {$[0.075856,0.075856]$} & {$[0.075856]$} & {$[0.075856]$} & {$[0.000542,20.55145]$} & {$[10.27599$} & {$[0.132279]$} & {$[0.00029,42.452]$} & {$[21,22615$} & {$[0,132048]$} \\
\hline Ag & {$[0.166245,0.166245]$} & {$[0.166245]$} & {$[0.166245]$} & {$[0.00113,20.10695]$} & {$[10.05404$} & {$[0.129422]$} & {$[0.000564,41.42961$} & {$[20,71509]$} & {$[0,128868]$} \\
\hline$A_{10}$ & {$[0.166245,0.166245]$} & {$[0.166245]$} & {$[0.166245]$} & {$[0.00113,20.10695]$} & 110.05404 & {$[0.129422]$} & {$[0.000564,41.42961$} & {$[20,71509$} & {$[0,128868]$} \\
\hline
\end{tabular}

Source: Authors' own research.

As shown in Table 7, the weight values approach each other as the data interval is increased by reducing the value of the level of $\alpha$-cut. In this situation, the overall ranking cannot be easily observed. In order to generate an overall ranking, it is suggested that a trade-off is chosen between the precision and the confidence. A higher $\alpha$ means that the interval chosen is precise, while a lower $\alpha$ means that there is a higher confidence in the result. A risk-averse assessor might choose a high alpha because of strong dislike of uncertainty (fuzziness), while a risk-taking assessor might prefer a low alpha.

By making use of the weight values determined by means of Shannon's entropy at certain $\alpha$-cut levels, we used the VIKOR method to determine the rank of alternatives, and to try to find a compromise result under the calculated weights, as one of the multi-criteria decision methods. This ranking was based on the customers' love of certain food and beverage locations identified by means of the VIKOR method. According to this, the results obtained by the fuzzy VIKOR algorithm are presented in Tables 8 and 9. 
Table 8. Fuzzy performance matrix of alternatives obtained by multiplying the normalized criteria weights in Table 7 for $\alpha 0.1$ levels

\begin{tabular}{|c|c|c|c|c|c|c|c|}
\hline \multirow[b]{2}{*}{ Criteria } & & \multicolumn{6}{|c|}{ Alternatives } \\
\hline & & $\begin{array}{c}\text { Soup } \\
\text { Restaurant }\end{array}$ & $\begin{array}{c}\text { Craft } \\
\text { Restaurant }\end{array}$ & $\begin{array}{l}\text { Fast-food } \\
\text { Restaurant }\end{array}$ & $\begin{array}{c}\text { Kebab } \\
\text { Restaurant }\end{array}$ & Cake Shop & $\begin{array}{c}\text { Regional Food } \\
\text { Restaurant }\end{array}$ \\
\hline \multirow{3}{*}{$\mathrm{A} 1+$} & $l$ & 0.015 & 0.023 & 0.005 & 0.004 & 0.000 & 0 \\
\hline & $\mathrm{m}$ & 0.014 & 0.023 & 0.004 & 0.004 & 0.000 & 0 \\
\hline & $\mathrm{r}$ & 0.006 & 0.020 & 0.002 & 0.003 & 0 & 0.003 \\
\hline \multirow{3}{*}{$\mathrm{A} 2+$} & $l$ & 0.019 & 0 & 0.011 & 0.006 & 0.004 & 0.007 \\
\hline & $\mathrm{m}$ & 0.019 & 0 & 0.013 & 0.006 & 0.004 & 0.007 \\
\hline & $\mathrm{r}$ & 0.013 & 0 & 0.012 & 0.005 & 0.008 & 0.008 \\
\hline \multirow{3}{*}{$\mathrm{A}^{3}+$} & $l$ & 0 & 0.017 & 0.009 & 0.013 & 0.004 & 0.0123 \\
\hline & $\mathrm{m}$ & 0 & 0.024 & 0.014 & 0.018 & 0.009 & 0.028 \\
\hline & $\mathrm{r}$ & 0 & 0,028 & 0.017 & 0.021 & 0.010 & 0.042 \\
\hline \multirow{3}{*}{$\mathrm{A} 5+$} & $l$ & 0.021 & 0.024 & 0.013 & 0.004 & 0 & 0.001 \\
\hline & $\mathrm{m}$ & 0.024 & 0.025 & 0.014 & 0.005 & 0 & 0.002 \\
\hline & $\mathrm{r}$ & 0.017 & 0.022 & 0.013 & 0.008 & 0 & 0.003 \\
\hline \multirow{3}{*}{$\mathrm{A} 6+$} & $l$ & 0.024 & 0.039 & 0 & 0.032 & 0.013 & 0.035 \\
\hline & $\mathrm{m}$ & 0.024 & 0.036 & 0 & 0.031 & 0.009 & 0.041 \\
\hline & $\mathrm{r}$ & 0.016 & 0.026 & 0.002 & 0.028 & 0 & 0.043 \\
\hline \multirow{3}{*}{$\mathrm{A} 8+$} & $l$ & 0.022 & 0.002 & 0,016 & 0 & 0.002 & 0.000 \\
\hline & $\mathrm{m}$ & 0.016 & 0 & 0.021 & 0.005 & 0.003 & 0.000 \\
\hline & $\mathrm{r}$ & 0.013 & 0 & 0.030 & 0.014 & 0.006 & 0.002 \\
\hline \multirow{3}{*}{$\mathrm{A} 9+$} & l & 0.034 & 0 & 0.018 & 0.017 & 0.027 & 0.013 \\
\hline & $\mathrm{m}$ & 0.032 & 0 & 0.027 & 0.024 & 0.029 & 0.017 \\
\hline & $\mathrm{r}$ & 0.031 & 0 & 0.035 & 0.031 & 0.030 & 0.020 \\
\hline \multirow{3}{*}{$\mathrm{AlO}+$} & $l$ & 0.034 & 0 & 0.018 & 0.017 & 0.027 & 0.013 \\
\hline & $\mathrm{m}$ & 0.032 & 0 & 0.027 & 0.024 & 0.029 & 0.017 \\
\hline & $\mathrm{r}$ & 0.031 & 0 & 0.035 & 0.031 & 0.030 & 0.020 \\
\hline
\end{tabular}

Source: Authors' own research.

Table 9. Metric values computed from the fuzzy performance matrix of alternatives in Table 8 for alpha 0.1 levels

\begin{tabular}{|c|c|c|c|c|c|c|c|}
\hline & & \multicolumn{6}{|c|}{ Alternatives } \\
\hline \multirow{5}{*}{ S } & & $\begin{array}{c}\text { Soup } \\
\text { Restaurant }\end{array}$ & $\begin{array}{c}\text { Craft } \\
\text { Restaurant }\end{array}$ & $\begin{array}{l}\text { Fast-food } \\
\text { Restaurant }\end{array}$ & $\begin{array}{c}\text { Kebab } \\
\text { Restaurant }\end{array}$ & Cake Shop & $\begin{array}{c}\text { Regional Food } \\
\text { Restaurant }\end{array}$ \\
\hline & $\mathrm{S}^{I}$ & 0.171 & 0.108 & 0.094 & 0.096 & 0.080 & 0.085 \\
\hline & $\mathrm{S}^{\mathrm{M}}$ & 0.165 & 0.110 & 0.124 & 0.120 & 0.086 & 0.115 \\
\hline & $\mathrm{S}^{\mathrm{I}}$ & 0.130 & 0.098 & 0.151 & 0.143 & 0.087 & 0.145 \\
\hline & Crisp S & 0.158 & 0.106 & 0.123 & 0.120 & 0.085 & 0.115 \\
\hline \multirow{4}{*}{$R$} & $\mathrm{~S}^{i}$ & 0.034 & 0.039 & 0.018 & 0.032 & 0.027 & 0.035 \\
\hline & $\mathrm{S}^{\mathrm{m}}$ & 0.032 & 0.036 & 0.027 & 0.031 & 0.029 & 0.041 \\
\hline & $\mathrm{S}^{\mathrm{I}}$ & 0.031 & 0.028 & 0.035 & 0.031 & 0.030 & 0.043 \\
\hline & Crisp R & 0.032 & 0.035 & 0.027 & 0.031 & 0.029 & 0.040 \\
\hline \multirow{4}{*}{ Q } & $\mathrm{S}^{l}$ & 0.252 & 0.375 & 1.438 & 0.765 & 1.105 & 0.693 \\
\hline & $\mathrm{S}^{\mathrm{m}}$ & 0.414 & 0.569 & 0.920 & 0.741 & 1.062 & 0.300 \\
\hline & $\mathrm{S}^{\mathrm{I}}$ & 0.703 & 1.020 & 0.373 & 0.640 & 0.996 & 0.031 \\
\hline & Crisp Q & 0.446 & 0.633 & 0.913 & 0.722 & 1.057 & 0.331 \\
\hline
\end{tabular}

Source: Authors' own research.

The results obtained for all levels of $\alpha$-cuts are shown in Tables 10-12:

Table 10. Ranking values for $\alpha=1$

\begin{tabular}{|c|c|c|c|}
\hline \multicolumn{2}{|r|}{$\alpha=1$} & $\mathbf{Q}$ & Ranking \\
\hline \multirow{6}{*}{ 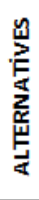 } & Regional Food Restaurant & 0,2100954 & 1 \\
\hline & Kebab Restaurant & 0,442821363 & 2 \\
\hline & Craft Restaurant & 0,456094173 & 3 \\
\hline & Soup Restaurant & 0,502912692 & 4 \\
\hline & Fast-food Restaurant & 0,955668822 & 5 \\
\hline & Cake Shop & 1,007880407 & 6 \\
\hline
\end{tabular}

Source: Authors' own research.

Table 11. Ranking values for $\alpha=0.5$

\begin{tabular}{|c|c|c|c|}
\hline \multicolumn{2}{|r|}{$\alpha=0.5$} & $\mathbf{Q}$ & Ranking \\
\hline \multirow{6}{*}{ 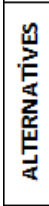 } & Regional Food Restaurant & 0,330892 & 1 \\
\hline & Kebab Restaurant & 0,717209 & 4 \\
\hline & Craft Restaurant & 0,634451 & 3 \\
\hline & Soup Restaurant & 0,440829 & 2 \\
\hline & Fast-food Restaurant & 0,90587 & 5 \\
\hline & Cake Shop & 1,049887 & 6 \\
\hline
\end{tabular}

Source: Authors' own research. 
Table 12. Ranking values for $\alpha=0.1$

\begin{tabular}{|c|c|c|c|}
\hline \multicolumn{2}{|r|}{$\alpha=0.1$} & $\mathbf{Q}$ & Ranking \\
\hline \multirow{6}{*}{ 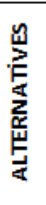 } & Regional Food Restaurant & 0,33133 & 1 \\
\hline & Kebab Restaurant & 0,722001 & 4 \\
\hline & Craft Restaurant & 0,633765 & 3 \\
\hline & Soup Restaurant & 0,446608 & 2 \\
\hline & Fast-food Restaurant & 0,913273 & 5 \\
\hline & Cake Shop & 1,057178 & 6 \\
\hline
\end{tabular}

Source: Authors' own research.

\section{Conclusions and recommendations}

The rapid evolution and development of technology reveals new consumption patterns due to various factors, such as socio-economic and cultural structures, and variations in consumer requirements. Retailers who struggle to satisfy the rapidly changing requests and requirements of consumers are faced with a seriously competitive environment. It is also important for retailers, who represent one sector of these mediators, to understand the variables affecting consumer preferences and preference structures. In addition, this competitive environment forces retailers to develop strategies in order to clarify their positions in consumers' minds and thus affect consumer preferences and become favoured over competitors. Therefore, the retailing sector constitutes a continuously changing, dynamic structure.

There are certain criteria by which consumers rank retailers, and the same criteria should be used when marketing products since consumers configure their preferences based on them. In this study, food and beverage locations were selected as retailer enterprises. The criteria for love, which is involved in location selection, and the effect of this love in the selection of alternative locations, were researched. While analysing the data, the criteria weighing method known as fuzzy Shannon's entropy was used. The reason for this is that consumers do not make decisions based solely on cognitive factors, and the decision-making process has a complex and often unclear structure.

In order to rank consumers' location preferences according to criteria, which was the secondary aim of the study, the fuzzy VIKOR method was used. This method was created via a hybridization of the fuzzy and VIKOR methods. The VIKOR method is a multi-criteria decision-making technique. For the fuzzy numbers that were used during the weighing of the criteria and the ranking of preferences, different $\alpha$-cut levels were used. The reason for this is that the fuzziness level differs at various $\alpha$ levels, and that these results affect the reliability of the analysis. A low $\alpha$ level represents more fuzziness and increased reliability of the results, while a high $\alpha$ level reveals increased clarity of the selected interval. However, in this study the increase in fuzziness, namely the $\alpha$ level in the uncertainty environment, was taken into consideration. In order to observe the sensitive changes in ranking consumer preferences, various $\alpha$ levels were taken into consideration; the rankings were compared, and the lowest $\alpha$ level was used in the final conclusion.

From the love-criteria ranking, it can be observed that different criterion gain weight for each $\alpha$ level. At the $\alpha=1$ level where the clarity is high, it was observed that the expression "I love this location!" was at the forefront, while "This location is totally awesome" was more prevalent at the $\alpha=0.5$ and $\alpha=0.1$ levels. In the ranking of alternative location preferences, for all $\alpha$ levels, locations serving regional Erzurum dishes were ranked in first place. At the $\alpha=1$ level, where the clarity is high, it was observed that kebab restaurants were ranked in second place, 
followed by craftsmen restaurants in third place, and then soup restaurants, fastfood restaurants and patisseries. For the $\alpha=0.5$ and $\alpha=0.1$ levels where the fuzziness (that is, uncertainty) increased, the ranking did not change. Regional restaurants were again ranked first, followed by soup restaurants, craftsmen restaurants, kebab restaurants, fast-food restaurants and patisseries. Accordingly, it can be said that regional tastes are most loved by the respondents, compared to the other restaurant types, and that patisseries were least loved for all respondents.

The results obtained from the analysis show that locations serving regional dishes have a strong image and are highly rated by consumers. However, it should not be forgotten that services and tastes will have played an important role in the establishment of this positive image. Another interesting result is that patisseries were always ranked last, which shows that the products and services offered by patisseries are insufficient in terms of creating differentiation for consumers, and thus are not preferred over any other restaurant types.

The results also show that the second-, third-, fourth-, fifth- and sixth-place locations change in cases of uncertainty. This result shows that these locations (soup restaurants, craftsmen restaurants, kebab restaurants, and fast-food restaurants) do not create a consistently strong enough image in the consumers' minds to be indispensable to consumers, and thus are interchangeable with one another. This represents a serious problem for these enterprises, which should review their strategies and revise them accordingly.

The importance of gaining customer love is clearly seen in this paper. Customer love provides competitive advantage through enabling positive communication of the retailers through their surroundings. This communication is important not only for the retailers, but also for every front office employee. The obtained results widen the horizon for retailers as well as for managers. All the information about customers is crucial these days which are faced with continuous improving and changing consumer needs. This is why businesses which know their customers will be a step ahead others. The businesses lacking this information will be condemned to fail in dynamic market conditions. Unless businesses know their customers, they will not satisfy the customers' request and needs.

Researchers who want to study about this topic in the future can improve the present research paper in different sectors and/or through adding different topics. Moreover this research can be conducted in different provinces and countries. Thus, benchmarking and competitiveness studies can be presented.

\section{References}

Ahuvia, A.C. (2005), "Beyond The extended self: loved objects and consumers' identity narratives", Journal of Consumer Research, Vol. 32, No. 1, pp. 171184.

Ajzen, I. (2005), Attitudes, Personality, and Behavior, McGraw-Hill International, New York.

Burns, D.J. and Neisner, L. (2006), "Customer satisfaction in a retail setting: the contribution of emotion", International Journal of Retail and Distribution Management, Vol. 34, No. 1, pp. 49-66.

Carroll, B.A. and Ahuvia, A.C. (2006), "Some antecedents and outcomes of brand love”, Marketing Letters, Vol. 17, No. 2, pp. 79-89. 
MMCKS Chaghooshi, A.J., Fathi, M.R. and Kashef, M. (2012), "Integration of Fuzzy Shannon's Entropy with fuzzy TOPSIS for industrial robotic system selection", Journal of Industrial Engineering \& Management, Vol. 5, No. 1, pp. 102-114.

Chen, C.-T. (2000), "Extensions of the topsis for group decision-making under fuzzy environment", Fuzzy Sets And Systems, Vol. 114, No. 1, pp. 1-9.

Chen, C.-T. (2001), "A fuzzy approach to select the location of the distribution center", Fuzzy Sets And Systems, Vol. 118, No. 1, pp. 65-73.

Chen, L.Y. and Wang, T.C. (2009), "Optimizing partners' choice in IS/IT outsourcing projects: The strategic decision of fuzzy VIKOR", International Journal of Production Economics, Vol. 120, No.1, pp. 233-242.

Ehrgott, M. (2005), Multicriteria Optimization Vol-2, Springer, Berlin.

Ghorbani, M., Arabzad, S.M. and Bahrami, M. (2012), "Implementing shannon entropy, SWOT and mathematical programming for supplier selection and order allocation", International Journal of Supply Chain Management, Vol. 1, No. 1, pp. 43-47.

Herrera, F. and Herrera-Viedma, E. (2000), "Linguistic decision analysis: steps for solving decision problems under linguistic information", Fuzzy Sets and systems, Vol. 115, No. 1, pp. 67-82.

Homburg, C. and Giering, A. (2001), "Personal characteristics as moderators of the relationship between customer satisfaction and loyalty-an empirical analysis", Psychology \& Marketing, Vol.18, No. 1, pp. 43-66.

Jani, D. and Han, H. (2011), "Investigating the key factors affecting behavioral intentions: evidence from a full-service restaurant setting", International Journal of Contemporary Hospitality Management, Vol. 23, No. 7, pp. 10001018.

Jones, M.A. and Suh, J. (2000), "Transaction-specific satisfaction and overall satisfaction: an empirical analysis", Journal Of Services Marketing, Vol. 14, No. 2, pp. 147-159.

Kabir, G. (2014), "Consultant selection for quality management using VIKOR method under fuzzy environment", International Journal of Multicriteria Decision Making, Vol. 4, No.2, pp. 96-113.

Kahraman, C., Ates, N.Y., Çevik, S., Gülbay, M. and Erdogan, S.A. (2007), "Hierarchical fuzzy topsis model for selection among logistics information technologies", Journal of Enterprise Information Management, Vol. 20, No. 2, pp. 143-168.

Kim, H. (2007), "Toward customer love: investigatıng the antecedents and outcomes of satisfied customers' emotional attachments to retailers", Doctor of Philosophy Degree Thesis, The University of Tenesse, Knoxville.

Kim, H.-Y., Kim, Y.-K., Jolly, L. and Fairhurst, A. (2008), "Satisfied customers' love toward retailers: a cross-product exploration", Advances In Consumer Research, Vol. 35, pp. 507-515.

Kim, H.-Y., Kim, Y.-K., Jolly, L. and Fairhurst, A. (2010), "The role of love in satisfied customers' relationships with retailers", The International Review Of Retail, Distribution And Consumer Research, Vol. 20, No. 3, pp. 285-296.

Klcinc, S.S. and Baker, S.M. (2004), "An integrative review of material possession attachment", Academy of Marketing Science Review, Vol. 2004, No. 1, pp. 1-35.

Ladhari, R. (2009), "Service quality, emotional satisfaction, and behavioural intentions: a study in the hotel industry", Managing Service Quality, Vol. 19, No. 3, pp. 308-331. 
Li, D.F. (2005), "Multiattribute decision making models and methods using intuitionistic fuzzy sets”, Journal of Computer and System Sciences, Vol. 70, No. 1, pp. 73-85.

Liu, H.W. and Wang, G.J. (2007), "Multi-criteria decision-making methods based on intuitionistic fuzzy sets", European Journal of Operational Research, Vol. 179, No. 1, pp. 220-233.

Lotfi, F.H. and Fallahnejad, R. (2010), “Imprecise Shannon's entropy and multi attribute decision making", Entropy, Vol. 12, No. 1, pp. 53-62.

Opricovic, S. (2007), "A Fuzzy compromise solution for multi criteria problems", International Journal of Uncertainty, Fuzziness And Knowledge-Based Systems, Vol. 15, No. 3, pp. 363-380.

Opricovic, S. and Tzeng, G.-H. (2004), "Compromise solution by MCDM methods: A comparative analysis of VIKOR and topsis", European Journal Of Operational Research, Vol. 156, No. 2, pp. 445-455.

Parkinson, B., Fischer, A.H. and Manstead, A.S. (2004), Emotion in Social Relations: Cultural, Group, and Interpersonal Processes, Psychology Press, London.

Sautter, P., Hyman, M.R. and Lukosius, V. (2004), "E-Tail Atmospherics: A Critique of the Literature and Model Extension", Journal of Electronic Commerce Research, Vol. 5, No. 1, pp. 14-24.

Shannon, C. E. (2001), "A mathematical theory of communication", ACM SIGMOBILE Mobile Computing and Communications Review, Vol. 5, No. 1, pp. 3-55.

Thomson, M., Macinnis, D.J. and Whan Park, C. (2005), "The ties that bind: measuring the strength of consumers' emotional attachments to brands", Journal Of Consumer Psychology, Vol. 15, No. 1, pp. 77-91.

Whang, Y.-O., Allen, J., Sahoury, N. and Zhang, H. (2004), "Falling in love with a product: the structure of a romantic consumer-product relationship", Advances In Consumer Research, Vol. 31, No. 1, pp. 320-327.

Zadeh, L.A. (1965), "Fuzzy sets", Information and Control, Vol. 8, No. 3, pp. 338-353.

Zadeh, L.A. (2008), "Is there a need for fuzzy logic?”, Information Sciences, Vol. 178, No. 13 , pp. 2751-2779.

Zadeh, L.A. (2009), "Toward extended fuzzy logic-A first step", Fuzzy Sets and Systems, Vol. 160, No. 21, pp. 3175-3181. 